Part of Journal of Research of the National Bureau of Standards, Volume 19, September 1937

\title{
MEASUREMENTS OF CERTAIN PHYSICOCHEMICAL CONSTANTS OF BENZENE
}

\author{
By Mieczysław Wojciechowski ${ }^{1}$
}

\begin{abstract}
A series of preparations of benzene of a high degree of purity were made by fractional distillation, by azeotropic distillation with ethanol, and by crystallization followed by centrifuging. The following physicochemical constants were measured: boiling point, $80.094 \pm 0.002^{\circ} \mathrm{C}$; freezing point, $5.51 \pm 0.01^{\circ} \mathrm{C}$; refractive index $n_{D}^{25}, 1.49807 \pm 0.00006$; and density at $25^{\circ} \mathrm{C}, 0.87366 \mathrm{~g} / \mathrm{cm}^{3}$ \pm 0.00002 . Previous determinations of these constants, as reported in the literature, are reviewed.
\end{abstract}

\section{CONTENTS}

I. Introduction

II. Methods of purification 348

III. Investigation of the degree of purity of the preparations._. 349

IV. Methods of measurement__. 349

V. Experimental results and conclusions

VI. References_._._.

\section{INTRODUCTION}

Many authors have measured the physicochemical constants of benzene. Determinations of its boiling point were published in the year 1895 by E. Beckmann and G. Fuchs [1] ${ }^{2}$ and in 1898 by G. Kahlbaum [2]. The large difference between the results of these authors led B. Woringer [3] to carry out another determination. In 1910 Sydney Young [4] measured the boiling point $\left(80.20^{\circ} \mathrm{C}\right)$ and density of benzene, and for many years his data were considered as the most reliable. In $1926 \mathrm{~J}$. Timmermans and F. Martin [5] measured the boiling and freezing points, refractive index, and density of benzene, confirming the data reported by Young. However, the data published by A. Zmaczynski [6] in 1930, which were obtained by the comparative method of measurement with modern ebulliometers of the Swiętosławski type, indicated that the accepted boiling point of benzene was in error. Later, this author published a second paper [7] reporting the boiling point of benzene as $80.110^{\circ} \mathrm{C}$, a value $0.012^{\circ}$ lower than that given in his first paper. This exceeds the possible error of the temperature determination by the comparative method, the difference being caused, probably, by a difference in the purity of the preparations investigated.

Benzene is a very important substance and may prove suitable as a standard for some physicochemical measurements. For example, there is need for stable liquids of high purity whose indices of refraction

\footnotetext{
1 Guest worker, from Polytechnic Institute, Warsaw, Poland.

3 The figures in brackets refer to references listed at the end of the paper.
} 
may be established to serve as standards supplementing water for the adjustment of refractometers. For this reason, it was desired to work out a reliable method for preparing it in a state of the highest purity as well as to redetermine the physicochemical constants, boiling and freezing points, refractive index, and density.

It is probable that many of the discrepancies of the results for physicochemical constants published by various authors have originated mainly in their attempts to carry out absolute measurements, instead of using the easier and more precise method of comparative measurements. In the present work emphasis was placed on careful purification by physical methods, of preparations previously purified by chemical means, and on proof that the final preparations were really of very high purity. Three different methods of purification were used, and as a result there were obtained several preparations which were tested for purity by the ebulliometric method [8] before the measurements of the physicochemical constants were made.

\section{METHODS OF PURIFICATION}

The initial material was a quantity of benzene which conformed to the specifications adopted by the American Chemical Society for this substance as an analytical reagent [9]. This material corresponded to the fifth degree of purity on the Swiettosławski scale, the difference between its boiling and condensation temperatures being $0.005^{\circ} \mathrm{C}$. Since the nature of the impurities in the initial substance was unknown and since by the aid of one method alone it would probably be impossible to remove all impurities, three different means of purification were applied.

For the purification of the benzene by the first method, 2 liters of the initial substance was fractionally distilled. A 40-bulb column of the Świętosławski type [10], with vacuum jacket, was used and adjusted so that the reflux ratio was $10: 1$ and the rate of distillation $20 \mathrm{ml}$ per hour. In this distillation equal volumes of head and tailings were rejected and five middle fractions of $200 \mathrm{ml}$ each were collected, labelled as preparations $A$ : $A_{a}, A_{b}, A_{\mathrm{I}}, A_{\mathrm{II}}$, and $A_{\mathrm{III}}$. Only fractions $A_{\mathrm{I}}, A_{\mathrm{II}}$, and $A_{\mathrm{III}}$ were used for the final measurement of properties.

The second portion was treated by crystallizing the benzene, centrifuging the mother liquor, and then distilling the crystal fraction. In this procedure, three liters of the initial preparation was used. The substance was cooled until about two-thirds of the total amount was crystallized. Then the crystals were crushed and the mother liquor removed from the mash, by the aid of a laboratory centrifuge constructed by R. T. Leslie and S. T. Schicktanz [11]. Next the crystals of benzene were melted and the liquid was distilled through the column. The fractions distilling at constant temperature within a limit of $0.001^{\circ}$ were collected. By this procedure seven fractions of $200 \mathrm{ml}$ each were obtained, designated as $B_{1}$ to $B_{7}$. The mother liquor was distilled separately until the same uniformity of boiling point was reached, and three fractions of $200 \mathrm{ml}$ were retained, designated as $C_{\mathrm{I}}$ to $C_{\mathrm{III}}$.

The third method was based on the azeotropic distillation of benzene with purified ethanol. Ethanol was then removed from the azeotropic mixture by washing out with water and the benzene distilled, only the middle fraction of the distillate being collected (preparation $D)$. A binary mixture of ethanol and benzene boils at a much lower 
temperature than pure benzene, and therefore higher-boiling impurities which do not form azeotropic mixtures with ethanol and benzene, such for instance as toluene, are easily removed. Only the middle fraction of the distillate, which distilled at practically constant temperature $\left( \pm 0.001^{\circ} \mathrm{C}\right)$, was collected for use. Then the benzene was separated from ethanol by the method of S. Young [12], by repeatedly washing out the alcohol with water. The preparation was finally distilled through the column to remove remaining minute quantities of ethanol and water.

\section{INVESTIGATION OF THE DEGREE OF PURITY OF THE PREPARATIONS}

Several criteria of purity were applied to the various preparations of benzene. The ebulliometric test of purity, based on the measurement of the difference $\Delta t$ between the boiling point and the temperature of condensation in the differential ebulliometer of standardized dimensions of the Swiętosławski type, indicated that all of the preparations were of a high degree of purity.

The second criterion of purity was the freezing behavior. Two of the fractions were frozen. In both cases the temperature of freezing was constant within $0.004^{\circ}$ until approximately two-thirds of the material was solid. Beyond this point adequate stirring for proper heat exchange in the mixture of solid and liquid could not be obtained.

Another test of purity was the comparison of boiling points of the successive fractions of distillation, and those of the preparations purified by various methods.

\section{METHODS OF MEASUREMENT}

Instead of the absolute measurements commonly used, which involve difficulties in calibrating apparatus, comparative measurements were employed for determining boiling point, density, and refractive index, using water as the reference liquid. The importance of comparative measurements to promote homogeneity of physicochemical data obtained in various laboratories has been emphasized in the literature by W. Swiętosławski [14].

The methods and apparatus used were as follows:

1. Boiling points were determined by means of the comparative method of $W$. Swiętosławski. For the measurements, a platinum resistance thermometer, constructed with a coiled filament designed by C. H. Meyers [15] and calibrated by the Heat Division of this Bureau, was used. The resistance of the thermometer was measured with a calibrated Mueller bridge. Measurements were reproduced within a precision of $0.001^{\circ} \mathrm{C}$.

2. Freezing points were measured with an apparatus described by B. J. Mair [16]. The freezing tube, containing about $50 \mathrm{ml}$ of benzene, was surrounded with an air jacket within an ice bath, for uniform cooling. A platinum resistance thermometer, the same that was used for measuring boiling points, was immersed in the freezing liquid. Stirring was done with a spiral surrounding the thermometer and moved up and down by an electric motor. Since water affects the freezing point of benzene, a current of dry air obtained by evaporation of liquid air was passed through the top of the tube, to avoid access of moisture. Somewhat more than two-thirds of each sample 
was frozen during the measurements. The freezing point of the preparations was practically constant, since the changes of temperature did not exceed $\pm 0.004^{\circ} \mathrm{C}$, and the accuracy of the measurements is estimated to be within $\pm 0.01^{\circ}$.

3 . The measurements of density were made at $25^{\circ} \mathrm{C}$ by the comparative method with the use of twin silica pycnometers [17]. The value $0.997044 \mathrm{~g} / \mathrm{cm}^{3}$ was used for the density of water at $25^{\circ} \mathrm{C}$.

4. The refractive index for the sodium $D$ lines was determined by means of a refractometer of the Abbe type, with the scale graduated to 0.0001 , calibrated by the Optical Instruments Section of this Bureau. The determinations were made at $25^{\circ} \mathrm{C}$. Water was used for adjusting the refractometer and the value of 1.33251 for its refractive index $n_{D}^{25}$, given in International Critical Tables, was taken. The accuracy of the measurements is believed to be \pm 0.00005 .

\section{EXPERIMENTAL RESULTS AND CONCLUSIONS}

The results of all the measurements are given in table 1.

TABLE 1.-Properties of the preparations of benzene

\begin{tabular}{|c|c|c|c|c|c|}
\hline Fraction & $\Delta t$ & $\begin{array}{c}\text { Normal } \\
\text { boiling } \\
\text { point }\end{array}$ & $\begin{array}{c}\text { Freezing } \\
\text { point }\end{array}$ & $n_{D}^{25}$ & $d_{25}$ \\
\hline & & ${ }^{\circ} \mathrm{C}$ & & 1. 49810 & $\mathrm{~g} / \mathrm{cm}^{5}$ \\
\hline$A_{\mathrm{I}-}$ & 0.003 & 80.096 & & $\begin{array}{l}\text { 1. } 49812 \\
1.49811\end{array}$ & 0.87364 \\
\hline$A_{\text {II }}$ & $\begin{array}{r}.000 \\
.002\end{array}$ & 80.097 & & 1. 49811 & $\begin{array}{r}.87366 \\
.87366\end{array}$ \\
\hline$A_{\text {III- }}$ & .002 & 80.097 & & 1. 49810 & .87358 \\
\hline $\begin{array}{l}B_{1--} \\
B_{2--}\end{array}$ & $\begin{array}{l}.002 \\
.002\end{array}$ & 80.092 & & $\begin{array}{l}\text { 1. } 49807 \\
\text { 1. } 49804\end{array}$ & .87367 \\
\hline$B^{3}$ & .001 & 80.093 & $-1-2-1$ & 1. 49804 & .87365 \\
\hline $\begin{array}{l}B^{4}- \\
B_{5-}\end{array}$ & $\begin{array}{l}.001 \\
.002\end{array}$ & $\begin{array}{l}80.093 \\
80.093\end{array}$ & 5. 51 & $\begin{array}{l}1.49804 \\
1.49804\end{array}$ & $\begin{array}{l}.87366 \\
87366\end{array}$ \\
\hline$B_{6-}$ & .002 & 80.093 & $-\ldots$ & 1. 49806 & .87367 \\
\hline$B_{7-\ldots}$ & .003 & 80.096 & & 1. 49804 & .87373 \\
\hline$C_{\mathrm{I}} \ldots \ldots$ & .002 & 80.091 & & $\begin{array}{l}1.49802 \\
1.49809\end{array}$ & $\begin{array}{l}.87366 \\
87368\end{array}$ \\
\hline 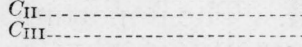 & $\begin{array}{l}.001 \\
.004\end{array}$ & $\begin{array}{l}80.093 \\
80.095\end{array}$ & 5. 51 & $\begin{array}{l}\text { 1. } 49809 \\
1.49809\end{array}$ & $\begin{array}{l}.87368 \\
.87361\end{array}$ \\
\hline$D_{\mathrm{I}-\ldots} \ldots$ & .001 & 80.093 & - & 1.49802 & .87367 \\
\hline Average & -....... & 80.094 & 5.51 & 1. 49807 & .87366 \\
\hline Probable error & & $\begin{array}{l} \pm .002 \\
\pm .001\end{array}$ & & 土. 00001 & 士. 00001 \\
\hline
\end{tabular}

The middle fractions of benzene purified by crystallization and by distillation of the binary azeotropic mixture with ethanol had differences between the boiling point and temperature of condensation equal to $0.001^{\circ} \mathrm{C}$. They had the same boiling point of $80.093^{\circ} \mathrm{C}$. Their high purity is evident from the fact that a number of successive fractions of distillate had the same $\Delta t$ and the same boiling point.

It is seen from table 1 that preparations $A$ having $\Delta t$, the difference between the boiling point and condensation temperature, equal to $0.002^{\circ} \mathrm{C}$, had the boiling point $80.097^{\circ} \mathrm{C}$, whereas preparations with the same $\Delta t$, purified by the other methods, had a boiling point of 80.091 to $80.093^{\circ} \mathrm{C}$. The preparations thus had a difference in boiling point of about $0.004^{\circ}$, although they had the same $\Delta t$. Since the standardized differential ebulliometer used for measuring the degree of purity has a rectifying efficiency equivalent to one theoretical plate [19], it cannot separate very minute amounts of impurities probably present in each preparation. These experiments show that when investigating preparations of extreme purity it is useful 
to compare their boiling points, employing the measurements of $\Delta t$ as a control to show that the preparation is really of the highest degree of purity on the Swiętosławski scale.

However, in view of the high purity of the initial material $(\Delta t=$ $\left.0.005^{\circ}\right)$, and its subsequent uniform improvement $(\Delta t=0.001$ to $0.003^{\circ}$ ) by each of the applied methods of purification, the averages of all determinations, without rejection of any single result or series, are taken for the final values of the measured properties.

The freezing curve was taken for the two middle fractions of the preparations $B$ and $C$. In both cases, as already mentioned, more than two-thirds of the sample investigated crystallized practically at constant temperature. The freezing point of both preparations was the same within the limits of experimental error and was equal to $5.51^{\circ} \mathrm{C}$.

Measurement of the refractive index has little significance as a criterion of purity of benzene, since this property is relatively insensitive to impurities but rather sensitive to changes of temperature. As an illustration, the following example may be reported. Benzene saturated with water at $25^{\circ} \mathrm{C}$ contains around 0.1 percent of water and has a refractive index lower by 0.00014 than benzene, water-free, whereas a change in temperature of $1^{\circ} \mathrm{C}$ causes a change in the refractive index $n_{D}^{25}$ of 0.00063 [20]. From all of the measurements made, the refractive index of benzene at $25^{\circ} \mathrm{C}$ for the sodium line $D$ may be taken as $1.49807 \pm 0.00006$.

The density of benzene at $25^{\circ} \mathrm{C}$ may be accepted as 0.87366 $\pm 0.00002 \mathrm{~g} / \mathrm{cm}^{3}$, the average of all the data obtained.

For comparison of the values obtained in the present work with those previously reported, the data published by other authors are listed in table 2.

TABLE 2.-Comparison of the resulbs with the data published by other authors

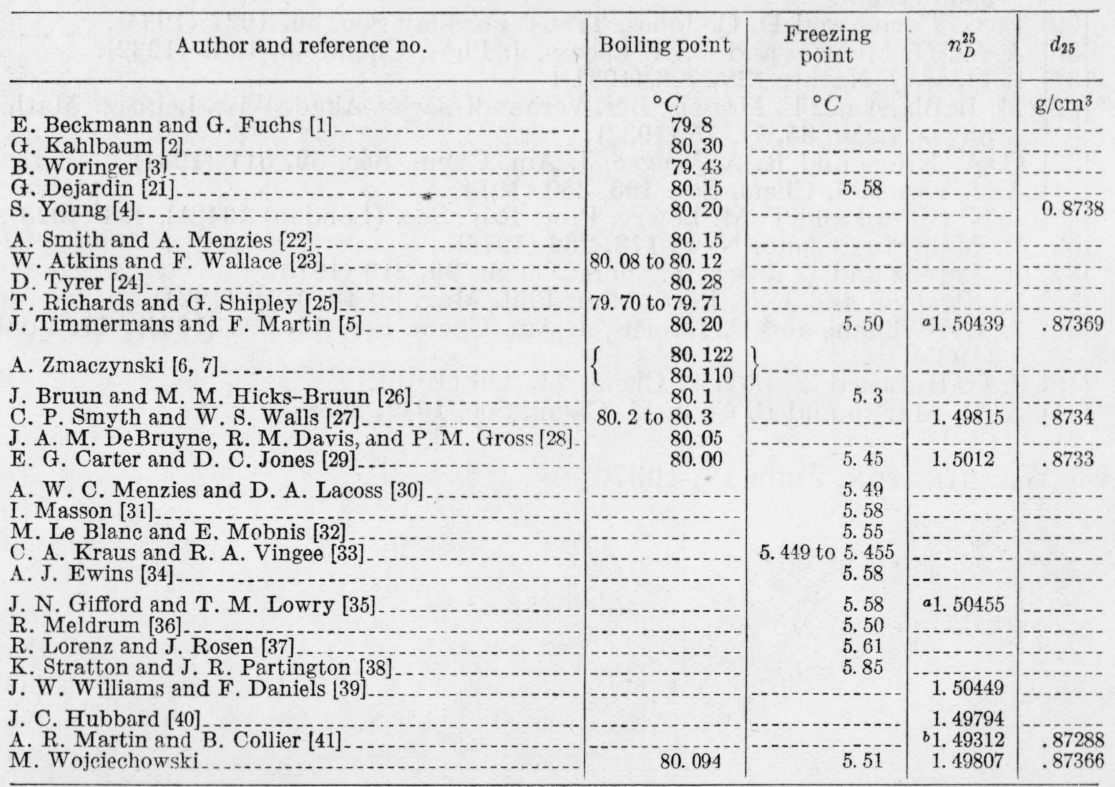


The author expresses his gratitude to the Polish Fundusz Kultury Narodowej (Polish Fund of National Culture), in Warsaw) for financial aid.

\section{REFERENCES}

[1] E. Beckmann and G. Fuchs, Z. physik. Chem. 18, 495 (1895).

[2] G. Kahlbaum, Z. physik. Chem. 26, 603 (1898).

[3] B. Woringer, Z physik. Chem. 34, 266 (1900).

[4] S. Young, Sci. Proc. Roy. Dublin Soc. 12, 374 (1910).

[5] J. Timmermans and F. Martin, J. chim. phys. 23, 747 (1926).

[6] A. Zmaczynski, J. chim. phys. 27, 503 (1930).

[7] A. Zmaczynski, Roczniki Chem. 14, 691 (1934).

[8] W. Swiętosławski, Bul. int. acad. polon. [A], 1930, 504; 1933, 177; Compt. rend. 192, 1457 (1931); Roczniki Chem. 13, 176, 227 (1933); Chem. Listy 26, 442 (1932);

[9] Ind. Eng. Chem., Anal. Ed. 4, 347 (1932).

[10] W. Swietosławski, J. chim. phys. 27, 329 (1930); Bul. soc. chim. [4] 49, 1563 (1931).

[11] R. T. Leslie and S. T. Schicktanz, BS J. Research 6, 377 (1931) RP282.

[12] S. Young, Distillation Principles and Processes, p. 192 (London, 1922).

[13] W. Swiętosławski, J. Phys. Chem. 38, 1169 (1934); IX Congreso Into Quim. Madrid 2,81 (1934).

[14] W. Swiętosławski, J. chim. phys. 27, 496 (1930).

[15] C. H. Meyers, BS J. Research 9, 807 (1932) RP508.

[16] B. J. Mair, BS J. Research 9, 457 (1932) RP482.

[17] E. R. Smith and M. Wojciechowski, Bul. int. acad. polon. [A], 1936, 281; Roczniki Chem. 16, 104 (1936).

[18] W. Swiętosławski, Annales acad. sci. techn. Varsovie 3, 28 (1936).

[19] E. R. Smith and M. Wojciechowski, J. Research NBS 17, 841 (1936) RP947.

[20] J. Timmermans and F. Martin, J. chim. phys. 23, 752 (1926).

[21] G. Déjardin, Ann. phys. 11, [9] 261 (1919).

[22] A. Smith and A. Menzies, J. Am. Chem. Soc. 32, 1452 (1910).

[23] W. Atkins and F. Wallace, J. Chem. Soc. 103, 1469 (1913).

[24] D. Tyrer, J. Chem. Soc. 105, 2538 (1914).

[25] T. Richards and G. Shipley, J. Am. Chem. Soc. 38, 926 (1916).

[26] J. Bruun and M. M. Hicks-Bruun, BS J. Research 6, 877 (1931) RP312.

[27] C. P. Smyth and W. S. Walls, J. Am. Chem. Soc. 54, 1857 (1932).

[28] J. A. M. De Bruyne, R. M. Davis and P. M. Gross, J. Am. Chem. Soc. 55, 3938 (1933).

[29] E. G. Carter and D. C. Jones, Trans. Faraday Soc. 30, 1027 (1934).

[30] A. W. C. Menzies and D. A. Lacoss, J. Phys. Chem. 36, 1967 (1932).

[31] I. Masson, Nature 128, 726 (1931).

[32] M. LeBlanc and E. Mobnis, Ber. Verhandl. sächs. Akad. Wiss. Leipzig. Math. phys. Klasse 85, II, 75 (1933).

[33] C. A. Kraus and R. A. Vingee, J. Am. Chem. Soc. 56, 511 (1934).

[34] A. J. Ewins, J. Chem. Soc. 105, 350 (1914).

[35] J. N. Gifford and T. M. Lowry, Proc. Roy. Soc. (London) 104[A], 434 (1923).

[36] R. Meldrum, Chem. News 113, 266 (1916).

[37] R. Lorenz and J. Rosen, Z. anorg. Chem. 96, 219 (1916).

[38] K. Stratton and J. R. Partington, Phil. Mag. [6] 48, 1059 (1924).

[39] J. W. Williams and F. Daniels, J. Am. Chem. Soc. 46, 903 (1924); 47, 1490 (1925).

[40] J. C. Hubbard, Z. physik. Chem. 74, 226 (1910).

[41] A. R. Martin and B. Collie, J. Chem. Soc. 1932, 2658.

Washington, June 18, 1937. 